\title{
Validity of EQ-5D-5L in stroke
}

\author{
Dominik Golicki • Maciej Niewada • Julia Buczek • Anna Karlińska • \\ Adam Kobayashi • M. F. Janssen - A. Simon Pickard
}

Accepted: 20 October 2014/Published online: 28 October 2014

(C) The Author(s) 2014. This article is published with open access at Springerlink.com

\begin{abstract}
Purpose To assess EQ-5D-5L (5L) validity in patients with acute stroke, in comparison with EQ-5D-3L (3L).

Methods Cross-sectional study of 408 patients during index hospitalization. We compared $5 \mathrm{~L}$ and $3 \mathrm{~L}$ in terms of feasibility, frequency of unique health states, ceiling effect and discriminatory power (informativity). We assessed construct validity in terms of known-groups validity and convergent validity of $5 \mathrm{~L}$ dimensions with other stroke outcome measures.

Results The overall proportion of patients with acute stroke reporting 'no problems' with $3 \mathrm{~L}-6.1 \%$ was further reduced to $5.6 \%$ with $5 \mathrm{~L}$ (relative reduction of $8.2 \%$ ). The highest improvement in relative discriminatory power, when moving from $3 \mathrm{~L}$ to $5 \mathrm{~L}$, was noticed in pain/discomfort and anxiety/depression dimensions (Shannon Evenness Index 0.91 for both $5 \mathrm{~L}$ dimensions; relative increase 34.4 and $29.1 \%$, respectively). Known-groups validity tests confirmed prior hypotheses: Health state utilities were lower in following subpopulations-females, patients with high modified Rankin Scale (mRS) score, low
\end{abstract}

D. Golicki $(\square) \cdot$ M. Niewada

Department of Experimental and Clinical Pharmacology,

Medical University of Warsaw, Banacha 1b St, 02-097 Warsaw,

Poland

e-mail: dominik.golicki@gmail.com

M. Niewada

e-mail: maciej.niewada@wum.edu.pl

J. Buczek · A. Karlińska · A. Kobayashi

2nd Department of Neurology, Institute of Psychiatry and

Neurology, Jana III Sobieskiego 9 St, 02-957 Warsaw, Poland

e-mail: jbuczek@ipin.edu.pl

A. Karlińska

e-mail: akarlinska@ipin.edu.pl
Barthel Index (BI) or VAS score, patients with subarachnoid hemorrhage or intracerebral hemorrhage, and when proxy respondent was used. Convergence of EQ-5D-5L dimensions with mRS, BI and EQ VAS was improved or at least the same as for $3 \mathrm{~L}$ dimensions.

Conclusions Results support the validity of the EQ-5D$5 \mathrm{~L}$ descriptive system as a generic health outcome measure in patients with acute stroke, demonstrating some psychometric advantages in comparison with EQ-5D-3L.

Keywords EQ-5D-5L - Health-related quality of life . Patient-reported outcomes · Psychometrics $\cdot$ Stroke

\section{Introduction}

Three level EQ-5D is, probably, the most widely used generic health status questionnaire in patients experiencing stroke [1, 2]. An extensive body of literature has been published, establishing its psychometric properties in stroke patients: reasonable construct, concurrent and

\footnotetext{
A. Kobayashi

e-mail: akobayas@ipin.edu.pl

M. F. Janssen

Department of Medical Psychology and Psychotherapy, Erasmus

MC, Erasmus University, PO Box 2040, 3000 CA Rotterdam,

The Netherlands

e-mail: mf.bas.janssen@gmail.com

\section{A. S. Pickard}

Department of Pharmacy Systems, Outcomes, and Policy,

College of Pharmacy, University of Illinois at Chicago, 833

South Wood St, MC886, Chicago, IL, USA

e-mail: pickard1@uic.edu
} 
discriminant validity, accuracy for predicting outcomes [35] and responsiveness in longitudinal studies [4, 6].

Recently, the EuroQol group has introduced new, five level, version of the EQ-5D (EQ-5D-5L) [7]. Janssen et al. [8], in multi-country study involving eight groups of patients with chronic conditions, demonstrated advantages of the new version: valid redistribution, reduced ceiling, improved discriminatory power and improved convergent validity (in comparison with the WHO-5 generic questionnaire). Several other validity studies in selected populations: Patients with chronic hepatic diseases [9], HIV/ AIDS [10] and cancer [11, 12], has been conducted. Nevertheless, specific analysis concerning stroke patients is still lacking.

The aim of our study was to assess the validity of the EQ-5D-5L, in comparison with EQ-5D-3L, in acute stroke patients.

\section{Methods}

\section{Patients}

Adult patients with cerebral infarction, intracranial or subarachnoid hemorrhage (I63, I61 or I60, according to the ICD10 classification) were included into a single center crosssectional study. A diagnosis had to be confirmed by clinical and neuroimaging examinations. Patients had to be Polish language native speakers. Patients in coma were excluded. In case of aphasia or dementia, the survey was completed by a family member serving as a proxy respondent.

\section{Measures}

The survey took place during index hospitalization (median 8 days since admission). The degree of disability due to stroke was assessed with the modified Rankin Scale (mRS) [2], physical performance with Barthel Index (BI) [13], and health-related quality of life with the EQ-5D-5L (5L) and EQ-5D-3L (3L) generic questionnaires and the visual analog scale (EQ VAS). Quality of life instruments were always presented in the fixed, mentioned above order, with no other questionnaires between the $5 \mathrm{~L}$ and $3 \mathrm{~L}$. Paper and pencil versions were used. To obtain $3 \mathrm{~L}$ index values, we used the Polish EQ-5D-3L value set based on the time trade-off valuation technique [14] and to obtain 5L index, we used Polish interim EQ-5D-5L value set estimated with official crosswalk methodology as developed by the EuroQol Group $[15,16]$. The study protocol was approved by the local ethics committee and all participants gave informed consent before inclusion.
Analysis

We compared $5 \mathrm{~L}$ and $3 \mathrm{~L}$ in terms of feasibility (proportion of missing answers), frequency of unique health states, ceiling effect (proportion of 'no problem' answers) and discriminatory power (informativity) [8,9]. We assessed construct validity in terms of known-groups validity and convergent validity of $5 \mathrm{~L}$ dimensions with $3 \mathrm{~L}$ dimensions and other stroke outcome measures.

The proportion and level of logical inconsistencies in pairs of $5 \mathrm{~L}$ and $3 \mathrm{~L}$ answers was analyzed as described by Janssen et al. [17]. Inconsistent responses were scored from 1 to 3 , according to the distance from the consistent level.

To assess discriminatory power, we calculated the Shannon Index $\left(H^{\prime}\right)$, which represents the absolute amount of captured informativity and the Shannon Evenness Index $\left(J^{\prime}\right)$, which reflects the rectangularity of a distribution regardless of the number of levels, as described elsewhere $[8,18]$. When a measure reaches the evenness of the distribution (rectangularity), $H^{\prime}$ approaches $1.58(3 \mathrm{~L})$ or 2.32 $(5 \mathrm{~L})$ and $J^{\prime}$ approaches 1.0, indicating maximum informativity captured by the instrument.

Known-groups construct validity was tested for $5 \mathrm{~L}$ and $3 \mathrm{~L}$ indexes in regard to: age and sex, type of respondent (patient or proxy), stroke type according to ICD-10, stroke outcome according to mRS, BI and EQ VAS [19]. We hypothesized that utility will be lower: with increasing age, in females, when the patient would be unable to respond by himself and a proxy respondent would be used, in patients with subarachnoid hemorrhage or intracerebral hemorrhage [20]. We expected that utilities will follow stroke outcomes assessed by other instruments.

Convergent validity was assessed by examining the strength of association between $5 \mathrm{~L}$ and $3 \mathrm{~L}$ dimensions with $\mathrm{mRS}$ score, BI score and EQ VAS and by comparing $5 \mathrm{~L}$ and $3 \mathrm{~L}$ dimensions between themselves using Spearman's rank correlation coefficient [19]. Strength of correlation was interpreted using the following criteria: absent $\left(r_{\mathrm{s}}<0.20\right)$, poor $\left(r_{\mathrm{s}}=0.20-0.34\right)$, moderate $\left(r_{\mathrm{s}}=\right.$ $0.35-0.50)$ or strong $\left(r_{\mathrm{s}}>0.50\right)$ [21]. We hypothesized that: (1) $5 \mathrm{~L}$ dimensions will have stronger correlations with $\mathrm{mRS}$, BI and EQ VAS than 3L dimensions, (2) $5 \mathrm{~L}$ dimensions that relate to functioning-Mobility (MO), Self-Care (SC) and Usual Activities (UA)-will more strongly correlate with stroke outcome measures (mRS and $\mathrm{BI})$ than $5 \mathrm{~L}$ pain/discomfort (PD) and anxiety/depression (AD) dimensions and (3) related $5 \mathrm{~L}$ and $3 \mathrm{~L}$ dimensions will have stronger correlations with each other.

The study data were analyzed using StatsDirect ver. 2.8.0 statistical software. 
Table 1 Demographic characteristics of studied population

\begin{tabular}{|c|c|}
\hline \multicolumn{2}{|l|}{ Patients characteristics } \\
\hline $\mathrm{N}$ & $408^{\mathrm{a}}$ \\
\hline \multicolumn{2}{|l|}{ Age, years, } \\
\hline Mean (SD) & $69.0(12.9)$ \\
\hline Range & $23-98$ \\
\hline Sex, F, $n(\%)$ & $198(48.5)$ \\
\hline \multicolumn{2}{|l|}{ Stroke type (ICD-10), $n(\%)$} \\
\hline Subarachnoid hemorrhage (I60) & $8(2.0)$ \\
\hline Intracerebral hemorrhage (I61) & $39(9.7)$ \\
\hline Cerebral infarction (I63) & $353(87.4)$ \\
\hline Stroke, not specified (I64) & $4(1.0)$ \\
\hline \multicolumn{2}{|l|}{$\mathrm{mRS}, n(\%)$} \\
\hline $0-2$ & $206(51.2)$ \\
\hline $3-4$ & $130(32.3)$ \\
\hline 5 & $66(16.4)$ \\
\hline Barthel Index, mean (SD) & $70.6(34.7)$ \\
\hline \multicolumn{2}{|l|}{ Barthel Index, n (\%) } \\
\hline $0-24$ & $62(15.4)$ \\
\hline $25-49$ & $40(9.9)$ \\
\hline $50-74$ & 47 (11.7) \\
\hline $75-99$ & $100(24.8)$ \\
\hline 100 & $154(38.2)$ \\
\hline VAS, mean (SD) & $49.5(26.2)$ \\
\hline \multicolumn{2}{|l|}{ VAS, $n(\%)$} \\
\hline $0-24$ & $78(19.7)$ \\
\hline $25-49$ & $82(20.7)$ \\
\hline $50-74$ & $159(40.2)$ \\
\hline $75-100$ & $77(19.4)$ \\
\hline EQ-5D-3L index, mean (SD) & $0.528(0.382)$ \\
\hline EQ-5D-5L index, mean (SD) & $0.526(0.375)$ \\
\hline \multicolumn{2}{|l|}{ Respondent, $n(\%)$} \\
\hline Patient & $315(77.2)$ \\
\hline Proxy & $93(22.8)$ \\
\hline
\end{tabular}

a Missing data included: age (2 patients), ICD-10 (4), mRS (6), Barthel Index (5), VAS (12), EQ-5D-3L index (15), EQ-5D-5L index (12)

\section{Results}

From July 2009 to May 2010, 408 patients (51.5 \% males), mean age 69.0 years were enrolled (Table 1 ).

A total of $2.9 \% 5 \mathrm{~L}$ and $3.7 \%$ 3L questionnaires had at least one missing answer, indicating good feasibility of both instruments in patients with stroke. For 5L, missing values ranged from $0.25 \%$ in $\mathrm{MO}$ to $1.5 \%$ in UA. The overall proportion of inconsistent $5 \mathrm{~L}$ responses (in comparison with $3 \mathrm{~L}$ responses) was $3.5 \%$, ranging from $2.2 \%$ for $\mathrm{MO}$ to $5.0 \%$ for UA and with $86 \%$ of inconsistencies being level 1, as defined by Janssen et al. [17]. The proportion of patients reporting 'no problems' was $6.1 \%$ for $3 \mathrm{~L}$ and $5.6 \%$ for $5 \mathrm{~L}$ (in comparison with $38.2 \%$ for BI, $5.0 \%$ for $\mathrm{mRS}$ and $2.5 \%$ for EQ VAS). The relative reduction of the ceiling effect in 5L comparing to $3 \mathrm{~L}(8.2 \%)$ was the highest in SC dimension $(13.5 \%)$, followed by MO (10.1\%), AD (9.1\%), UA and PD (6.2\%, both). Shannon Index and Shannon Evenness Index showed perfect informativity of 5L MO dimension $\left(H^{\prime}=2.31 ; J^{\prime}=1.00\right)$ and nearly perfect informativity of 5L UA $\left(H^{\prime}=2.27 ; \quad J^{\prime}=0.98\right)$ and $\mathrm{SC}$ dimensions $\left(H^{\prime}=2.26 ; J^{\prime}=0.97\right)$, in patients with stroke. Nevertheless, the highest improvement in informativity, when moving from $3 \mathrm{~L}$ to $5 \mathrm{~L}$, was noticed in $\mathrm{PD}$ and $\mathrm{AD}$ dimensions (relative increase of 34.4 and $29.1 \% ; J^{\prime}=0.91$ for both $5 \mathrm{~L}$ dimensions, respectively). The total number of unique health states was 213 for 5L (most frequent 11,$111 ; n=22$ ) and 62 for $3 \mathrm{~L}$ (most frequent 22,222; $n=92$ ).

Results for known-groups construct validity are shown in Table 2. In general, the results confirmed our hypotheses: index-based scores were lower in females, patients with high $\mathrm{mRS}$ score, low BI or VAS score, patients with subarachnoid hemorrhage (I60) or intracerebral hermorrhage (I61), and when the patient was unable to respond by him/herself and a proxy respondent was necessary. The only unexpected result was a lower health utility in patients up to 60 years of age, comparing to 61-70 years group. Index-based scores were similar for both $5 \mathrm{~L}$ and $3 \mathrm{~L}$.

Moderate to strong correlations were found between $5 \mathrm{~L}$ and $\mathrm{mRS}, \mathrm{BI}$ and EQ VAS, with a minimum of -0.37 between PD and BI, and a maximum of 0.79 between UA and mRS (Table 3). In all cases, convergence of $5 \mathrm{~L}$ dimensions was improved or at least the same as $3 \mathrm{~L}$ dimensions. EQ-5D-5L MO, SC and UA dimensions were more strongly correlated with mRS and BI, than 5L PD and $\mathrm{AD}$ dimensions. Convergence between related $5 \mathrm{~L}$ and $3 \mathrm{~L}$ dimensions (Table 3, cells in italics) was better than between unrelated dimensions.

\section{Discussion}

According to our best knowledge, this is the first study reporting specific data on the validity of the EQ-5D-5L in stroke patients. We confirmed construct validity of the instrument in terms of known-groups and convergence validity with other established stroke outcome measures.

Known-groups validity showed similar results for both 5L and 3L. Index-based scores were lower in hypothesized subpopulations. Studying known-groups validity, we were surprised by the lower health state utilities in patients up to 60 years of age, comparing to the next age group. These results can be explained by a higher proportion of individuals with subarachnoid or intracerebral hemorrhagestroke types associated with worse outcome (29.3\% compared to $8.2 \%$ in older age groups). 
Table 2 Known-groups construct validity: mean index-based scores of EQ-5D5L and EQ-5D-3L (and $95 \%$ confidence intervals) by patient characteristics

\begin{tabular}{|c|c|c|c|c|}
\hline & \multicolumn{2}{|c|}{ EQ-5D-5L } & \multicolumn{2}{|c|}{ EQ-5D-3L } \\
\hline & $n$ & Mean $(95 \% \mathrm{CI})$ & $n$ & Mean $(95 \% \mathrm{CI})$ \\
\hline \multicolumn{5}{|c|}{ Age (years) } \\
\hline $0-60$ & 98 & $0.587(0.523 ; 0.651)$ & 95 & $0.595(0.527 ; 0.663)$. \\
\hline $61-70$ & 103 & $0.623(0.554 ; 0.693)$ & 104 & $0.612(0.542 ; 0.681)$ \\
\hline $71-80$ & 112 & $0.461(0.390 ; 0.531)$ & 111 & $0.473(0.405 ; 0.542)$ \\
\hline$>80$ & 81 & $0.428(0.335 ; 0.522)$ & 81 & $0.422(0.322 ; 0.523)$ \\
\hline \multicolumn{5}{|l|}{ Sex } \\
\hline Female & 193 & $0.485(0.428 ; 0.541)$ & 189 & $0.485(0.427 ; 0.543)$ \\
\hline Male & 203 & $0.565(0.517 ; 0.614)$ & 204 & $0.567(0.518 ; 0.617)$ \\
\hline \multicolumn{5}{|c|}{ Stroke type (ICD-10) } \\
\hline I60 & 7 & $0.292(-0.134 ; 0.719)$ & 8 & $0.390(0.016 ; 0.764)$ \\
\hline I61 & 37 & $0.456(0.309 ; 0.603)$ & 35 & $0.399(0.222 ; 0.576)$ \\
\hline I63 & 345 & $0.539(0.501 ; 0.578)$ & 342 & $0.545(0.506 ; 0.583)$ \\
\hline \multicolumn{5}{|c|}{ Modified Rankin Scale } \\
\hline 5 & 65 & $-0.027(-0.099 ; 0.044)$ & 65 & $-0.027(-0.098 ; 0.044$ \\
\hline 4 & 55 & $0.291(0.205 ; 0.377)$ & 56 & $0.271(0.181 ; 0.360)$ \\
\hline 3 & 70 & $0.576(0.522 ; 0.630)$ & 71 & $0.597(0.550 ; 0.644)$ \\
\hline 2 & 112 & $0.698(0.666 ; 0.730)$ & 108 & $0.705(0.668 ; 0.742)$ \\
\hline 1 & 68 & $0.824(0.794 ; 0.855)$ & 68 & $0.828(0.793 ; 0.863)$ \\
\hline 0 & 20 & $0.865(0.785 ; 0.946)$ & 19 & $0.884(0.829 ; 0.939)$ \\
\hline \multicolumn{5}{|c|}{ Barthel Index } \\
\hline $0-50$ & 107 & $0.069(0.008 ; 0.130)$ & 107 & $0.079(0.017 ; 0.140)$ \\
\hline $55-95$ & 134 & $0.610(0.572 ; 0.649)$ & 133 & $0.601(0.557 ; 0.645)$ \\
\hline 100 & 150 & $0.783(0.758 ; 0.808)$ & 148 & $0.795(0.771 ; 0.819)$ \\
\hline \multicolumn{5}{|l|}{ EQ VAS } \\
\hline $0-24$ & 76 & $-0.002(-0.069 ; 0.066)$ & 76 & $0.002(-0.074 ; 0.779$ \\
\hline $25-49$ & 78 & $0.428(0.362 ; 0.495)$ & 79 & $0.437(0.371 ; 0.502)$ \\
\hline $50-74$ & 157 & $0.670(0.637 ; 0.703)$ & 156 & $0.674(0.641 ; 0.708)$ \\
\hline $75-100$ & 77 & $0.855(0.829 ; 0.882)$ & 75 & $0.856(0.831 ; 0.880)$ \\
\hline \multicolumn{5}{|c|}{ Respondent } \\
\hline Patient & 306 & $0.653(0.623 ; 0.682)$ & 303 & $0.650(0.619 ; 0.682)$ \\
\hline Proxy & 90 & $0.096(0.016 ; 0.176)$ & 90 & $0.114(0.031 ; 0.196)$ \\
\hline
\end{tabular}

Table 3 Convergent validity with stroke outcome measures (mRS and BI), EQ VAS and EQ-5D-3L dimensions; cells with related 5L and 3L dimensions marked in italics

\begin{tabular}{|c|c|c|c|c|c|c|c|c|c|c|c|c|}
\hline \multirow[t]{2}{*}{ Dimension } & \multicolumn{2}{|l|}{$\mathrm{mRS}$} & \multicolumn{2}{|l|}{$\mathrm{BI}$} & \multicolumn{2}{|c|}{ EQ VAS } & \multirow{2}{*}{$\begin{array}{l}\text { EQ-5D-5L } \\
\text { dimensions }\end{array}$} & \multicolumn{5}{|c|}{ EQ-5D-3L dimensions } \\
\hline & $5 \mathrm{~L}$ & $3 \mathrm{~L}$ & $5 \mathrm{~L}$ & $3 \mathrm{~L}$ & $5 \mathrm{~L}$ & $3 \mathrm{~L}$ & & MO & $\mathrm{SC}$ & UA & PD & $\mathrm{AD}$ \\
\hline MO & 0.75 & 0.75 & -0.74 & -0.72 & -0.74 & -0.71 & MO & 0.87 & 0.78 & 0.74 & 0.51 & 0.44 \\
\hline $\mathrm{SC}$ & 0.78 & 0.78 & -0.77 & -0.76 & -0.75 & -0.72 & $\mathrm{SC}$ & 0.79 & 0.91 & 0.80 & 0.38 & 0.42 \\
\hline UA & 0.79 & 0.74 & -0.74 & -0.69 & -0.76 & -0.75 & UA & 0.77 & 0.82 & 0.87 & 0.37 & 0.42 \\
\hline $\mathrm{PD}$ & 0.42 & 0.36 & -0.37 & -0.33 & -0.55 & -0.43 & PD & 0.47 & 0.49 & 0.50 & 0.70 & 0.48 \\
\hline $\mathrm{AD}$ & 0.44 & 0.40 & -0.43 & -0.39 & -0.54 & -0.47 & $\mathrm{AD}$ & 0.46 & 0.48 & 0.51 & 0.49 & 0.71 \\
\hline
\end{tabular}

$A D$ anxiety/depression, $M O$ mobility, $P D$ pain/difficulty, $S C$ self-care, $U A$ usual activities, $m R S$ modified Rankin Scale, $B I$ Barthel Index

Furthermore, our results support convergence validity of EQ-5D-5L with other stroke measures. As expected, we found moderate to strong correlations between $5 \mathrm{~L}$ dimensions and mRS, BI or VAS. All coefficients were slightly higher or at least the same for $5 \mathrm{~L}$, in comparison with $3 \mathrm{~L}$. 
Our results are in general in line with these obtained by other authors in different populations [8, 9, 11]. EQ-5D-5L has shown some advantages in comparison with $3 \mathrm{~L}$ : slightly better feasibility and some improvement in informativity (especially in $\mathrm{PD}$ and $\mathrm{AD}$ dimensions). In distinction to other studied populations, we have noticed rather small reduction of ceiling effect, both in terms of absolute and relative reduction. This can be partially explained by low level of 'no problem' in acute stroke population at baseline (about $6 \%$ ). From the other side, Janssen et al. [8] indicated some populations with lowbaseline ceiling effect (rheumatoid arthritis patients) and substantial relative improvement (about $70 \%$ ).

Our study has some limitations. Quality of life questionnaires were administered in the fixed order. This could affect the proportion of missing answers, which was lower for 5L (administered first). The desirable solution would be to present instruments in a random order. Second, there were no other questionnaires presented between 5L and 3L. The risk is that memory effects may affect the comparison of these two versions.

Although, there is some evidence supporting the use of proxy respondents for $3 \mathrm{~L}[22,23]$, to our knowledge, this is one of the first studies that examines the validity of proxy respondents using the EQ-5D-5L. Further studies, also with longitudinal design, are needed to assess other psychometric characteristics in stroke patients, such as responsiveness to change and reliability of the instrument in terms of test-retest.

To conclude, evidence supports the EQ-5D-5L descriptive system as a valid generic health outcome measure in patients experiencing acute stroke, with some psychometric advantages in comparison with the EQ-5D3L.

Acknowledgments This research was supported in part by the EuroQol Group.

Conflict of interest Three authors disclose that they are members of the EuroQol Group, a not-for-profit organization that develops and distributes instruments that assess and value health.

Open Access This article is distributed under the terms of the Creative Commons Attribution License which permits any use, distribution, and reproduction in any medium, provided the original author(s) and the source are credited.

\section{References}

1. Brooks, R. (1996). EuroQol: The current state of play. Health Policy, 37(1), 53-72.

2. Quinn, T. J., Dawson, J., Walters, M. R., \& Lees, K. R. (2009). Functional outcome measures in contemporary stroke trials. International Journal of Stroke, 4(3), 200-205. doi:10.1111/j. 1747-4949.2009.00271.x.
3. Dorman, P. J., Waddell, F., Slattery, J., Dennis, M., \& Sandercock, P. (1997). Is the EuroQol a valid measure of health-related quality of life after stroke? Stroke, 28(10), 1876-1882.

4. Hunger, M., Sabariego, C., Stollenwerk, B., Cieza, A., \& Leidl, R. (2012). Validity, reliability and responsiveness of the EQ-5D in German stroke patients undergoing rehabilitation. Quality of Life Research, 21(7), 1205-1216. doi:10.1007/s11136-011-0024-3.

5. Pinto, E. B., Maso, I., Vilela, R. N., Santos, L. C., \& OliveiraFilho, J. (2011). Validation of the EuroQol quality of life questionnaire on stroke victims. Arquivos de Neuro-Psiquiatria, 69(2b), 320-323.

6. Pickard, A. S., Johnson, J. A., \& Feeny, D. H. (2005). Responsiveness of generic health-related quality of life measures in stroke. Quality of Life Research, 14(1), 207-219.

7. Herdman, M., Gudex, C., Lloyd, A., Janssen, M., Kind, P., Parkin, D., et al. (2011). Development and preliminary testing of the new five-level version of EQ-5D (EQ-5D-5L). Quality of Life Research, 20(10), 1727-1736. doi:10.1007/s11136-011-9903-x.

8. Janssen, M. F., Pickard, A. S., Golicki, D., Gudex, C., Niewada, M., Scalone, L., et al. (2013). Measurement properties of the EQ5D-5L compared to the EQ-5D-3L across eight patient groups: A multi-country study. Quality of Life Research, 22(7), 1717-1727. doi:10.1007/s11136-012-0322-4.

9. Scalone, L., Ciampichini, R., Fagiuoli, S., Gardini, I., Fusco, F., Gaeta, L., et al. (2013). Comparing the performance of the standard EQ-5D 3L with the new version EQ-5D 5L in patients with chronic hepatic diseases. Quality of Life Research, 22(7), 1707-1716. doi:10.1007/s11136-012-0318-0.

10. Tran, B. X., Ohinmaa, A., \& Nguyen, L. T. (2012). Quality of life profile and psychometric properties of the EQ-5D-5L in HIV/ AIDS patients. Health and Quality of Life Outcomes, 10, 132. doi:10.1186/1477-7525-10-132.

11. Kim, S. H., Kim, H. J., Lee, S. I., \& Jo, M. W. (2012). Comparing the psychometric properties of the EQ-5D-3L and EQ-5D-5L in cancer patients in Korea. Quality of Life Research, 21(6), 1065-1073. doi:10.1007/s11136-011-0018-1.

12. Lee, C. F., Luo, N., Ng, R., Wong, N. S., Yap, Y. S., Lo, S. K., et al. (2013). Comparison of the measurement properties between a short and generic instrument, the 5-level EuroQoL Group's 5-dimension (EQ-5D-5L) questionnaire, and a longer and disease-specific instrument, the Functional Assessment of Cancer Therapy-Breast (FACT-B), in Asian breast cancer patients. Quality of Life Research, 22(7), 1745-1751. doi:10.1007/s11136012-0291-7.

13. Quinn, T. J., Langhorne, P., \& Stott, D. J. (2011). Barthel index for stroke trials: Development, properties, and application. Stroke, 42(4), 1146-1151. doi:10.1161/strokeaha.110.598540.

14. Golicki, D., Jakubczyk, M., Niewada, M., Wrona, W., \& Busschbach, J. J. (2010). Valuation of EQ-5D health states in Poland: First TTO-based social value set in Central and Eastern Europe. Value in Health, 13(2), 289-297. doi:10.1111/j.1524-4733.2009. 00596.x.

15. van Hout, B., Janssen, M. F., Feng, Y. S., Kohlmann, T., Busschbach, J., Golicki, D., et al. (2012). Interim scoring for the EQ5D-5L: Mapping the EQ-5D-5L to EQ-5D-3L value sets. Value in Health, 15(5), 708-715. doi:10.1016/j.jval.2012.02.008.

16. Golicki, D., Niewada, M., van Hout, B., Janssen, M. F., \& Pickard, A. S. (2014). Interim EQ-5D-5L value set for Poland: First crosswalk value set in Central and Eastern Europe. Value in Health Regional Issues, 4C, 19-23.

17. Janssen, M. F., Birnie, E., Haagsma, J. A., \& Bonsel, G. J. (2008). Comparing the standard EQ-5D three-level system with a fivelevel version. Value in Health, 11(2), 275-284. doi:10.1111/j. 1524-4733.2007.00230.x.

18. Shannon, C. E. (1948). A mathematical theory of communication. The Bell System Technical Journal, 27, 379-423. 
19. Fayers, P. M., \& Machin, D. (2007). Scores and measurements: validity, reliability, sensitivity. Quality of life: The assessment, analysis and interpretation of patient-reported outcomes (pp. 77-108). Chichester: Wiley.

20. Niewada, M., Kobayashi, A., Sandercock, P. A., Kaminski, B., \& Czlonkowska, A. (2005). Influence of gender on baseline features and clinical outcomes among 17,370 patients with confirmed ischaemic stroke in the international stroke trial. Neuroepidemiology, 24(3), 123-128. doi:10.1159/000082999.

21. Juniper, E. F., Guyatt, G. H., \& Jaeschke, R. (1996). Chapter 6: How to develop and validate a new health-related quality of life instrument. In B. Spilker (Ed.), Quality of life and pharmacoeconomics in clinical trials (2nd ed., pp. 49-56). Philadelphia: Lippincott-Raven Publishers.

22. Dorman, P. J., Waddell, F., Slattery, J., Dennis, M., \& Sandercock, P. (1997). Are proxy assessments of health status after stroke with the EuroQol questionnaire feasible, accurate, and unbiased? Stroke, 28(10), 1883-1887.

23. Pickard, A. S., Johnson, J. A., Feeny, D. H., Shuaib, A., Carriere, K. C., \& Nasser, A. M. (2004). Agreement between patient and proxy assessments of health-related quality of life after stroke using the EQ-5D and Health Utilities Index. Stroke, 35(2), 607-612. doi:10.1161/01.str.0000110984.91157.bd. 